\title{
Management of idiopathic clubfoot by Ponseti's method: a comparative clinical study on toddlers with radiological correlation
}

\author{
Rishabh Kumar $^{1 *}$, Anshupriya ${ }^{2}$
}

\author{
${ }^{1}$ Senior Resident, Department of Orthopaedics, Katihar Medical College, Katihar, Bihar-854105, India \\ ${ }^{2}$ Junior Resident, Department of Radiodiagnosis, Katihar Medical College, Katihar, Bihar-854105, India
}

Received: 30 May 2016

Accepted: 03 June 2016

\author{
*Correspondence: \\ Dr. Rishabh Kumar, \\ E-mail: drrishabh2005@gmail.com
}

Copyright: (C) the author(s), publisher and licensee Medip Academy. This is an open-access article distributed under the terms of the Creative Commons Attribution Non-Commercial License, which permits unrestricted non-commercial use, distribution, and reproduction in any medium, provided the original work is properly cited.

\begin{abstract}
Background: In developed countries, many children with clubfoot undergo extensive corrective surgery, often with disturbing failures and complications. The need for one or more revision surgeries is common. Although the foot looks better after surgery, it is stiff, weak, and often painful. Non-operative treatment of clubfoot provides a lower complication rate, less pain, and higher function as the patient ages. Lack of information regarding reasons for adherence to the regimen makes it difficult for health providers and health planners to determine the impact of treatments on health status or weigh the cost/benefit ratio for prescribing costly treatments to the patients. Therefore, it is important to understand how parents and health care givers manage their children's treatment and the potential barriers these parents encounter during the utilization of clubfoot treatment services. It is important to determine the compliance of patients to clubfoot correction treatment in order to identify and target factors that may positively or negatively influence cases attending the clinic.

Methods: 25 cases with clubfoot were studied in the Department of Orthopaedics, Katihar Medical College. Out of these, 13 cases (Group A) were children over 1 year of age with neglected clubfoot and 12 cases (Group B) were children under one year of age with idiopathic clubfoot.

Results: The Ponseti method delivers excellent correction of clubfoot without the associated risks and complications of major foot surgery. Patients treated with Ponseti's method have leverage in treatment of clubfoot than those treated by other conservative methods. The method provides more flexible foot and ankle than those treated surgically.

Conclusions: Treatment of clubfoot if commenced early will have better result. Children of age less than 1 year respond better than children of older age group. Younger children require fewer correction casts.
\end{abstract}

Keywords: Clubfoot, Idiopathic, Neglected, Ponseti

\section{INTRODUCTION}

Clubfoot is defined as fixation of the foot in adduction, supination and varus. It is a deformity where the foot points downward with the toes and sole twisted inwards. Three bones the calcaneus, navicular, cuboid are medially rotated in relation to the talus. Idiopathic clubfoot is the commonest congenital deformity of foot. ${ }^{1}$ The incidence is about 1:1000 live births with a sex ratio of 2:1 showing preponderance among males. The condition is bilateral in about $50 \%$ of cases. $24.4 \%$ of affected individuals have a family history of idiopathic clubfoot. ${ }^{2}$

Most are untreated or poorly treated. Neglected clubfoot causes physical, social, psychological and financial burdens on the patients, their families, and the society. Globally, neglected clubfoot is the most serious cause of physical disability among congenital musculoskeletal disorders. ${ }^{3}$ The idiopathic type is primarily a deformity of soft tissue only. Although the primary cause is unknown, but mal-alignment and loss of flexibility of the 
talocalcaneonavicular joint complex appears mainly due to genetically determined discrepancy resulting in differential growth between the bone, joints and related soft tissues. Vascular anomalies, anomalous muscles and intrauterine factors have been reported.

The essential features of all types of clubfoot are equines of the talus at ankle joint, inversion of calcaneus at subtalar joint and supination of forefoot at talocalcaneal and calcaneocuboid joints. The muscles are poorly developed and tendons attenuated. Tendocalcaneus passes downward and inward into its insertion on calcaneus. The plantar muscles especially of medial side are contracted. The anterior and lateral muscles of the leg are elongated.

The ligaments on the medial and posterior surfaces of talonavicular joint, the deltoid ligament and plantar calcaneonavicular ligament are contracted. There is no widely accepted method to classify the initial characteristics and severity of the foot. Assessment of clubfoot is very important in management. Assessment is made by clinical and radiological data. ${ }^{4}$

Different modalities of treatment are available with their advantages and disadvantages. Non-operative treatment of idiopathic clubfoot is accepted worldwide as the initial standard. $^{5}$

Non-operative treatment of clubfoot provides a lower complication rate, less pain, and higher function as the patient ages than operative treatment. Imaging in the form of conventional radiography, has been used in the assessment of clubfoot.

The ossification centres of talus, calcaneus, cuboid and metatarsals are present at birth. So lines drawing through these ossification centres give us some idea about the alignment of the foot bones. These angles provide an impression about the deformity.

There is difference between radiological axis and true axis. Adduction given mainly by the talonavicular joint cannot be assessed as we cannot see the unossified navicular bone in neonates. Although talonavicular angle was replaced by talo- $1^{\text {st }}$ metatarsal angle, it continues to be elusive. The advent of new imaging modalities, such as musculoskeletal ultrasound has given us tools to visualize cartilages non-invasively.

This modality of investigation has been used very sparingly in the available world literature. Ultrasound can give us better picture of the whole bone and thus the grade of mal-alignment. Clinically, Pirani scoring is used to assess the severity of clubfoot. Recently the noninvasive treatment of clubfoot, developed by Dr. Ignacio Ponseti, has been shown to have a success rate about 95 $\%$ and best long-term outcomes. The Ponseti method is fast becoming the gold standard for clubfoot treatment and is currently being implemented all over the world.
The Ponseti technique is a well-proven way of managing paediatric clubfoot deformity.

The Ponseti method for treatment of idiopathic clubfeet involves the use of serial casts, percutaneous Achilles tenotomy in most cases and bracing with an abduction orthosis to prevent relapse. The method has been suggested as being particularly suited to the developing world because of its inherent simplicity and conservative methodology.

Early recognition and appropriate treatment of recurrent deformity is an important component of the Ponseti technique of clubfoot correction. Surgery in clubfoot is indicated for deformities that do not respond to the conservative treatment. ${ }^{6}$ Often in children with significant rigid clubfoot deformity, corrective surgery must be tailored to the age of the child and to the deformity to be corrected.

\section{METHODS}

This study was undertaken in the Department of Orthopaedics, Katihar Medical College, Katihar. Cases were selected from the outdoor clinics of the Department of Orthopaedics and the Department of Paediatrics.

\section{Inclusion criteria}

- Group A contains 13 Toddlers of age more than 1year with neglected clubfoot

- Group B contains 12 Toddlers of age up to age 1 year with idiopathic clubfoot

\section{Exclusion criteria}

- Secondary clubfoot

- Non idiopathic congenital Talipes Equino Varus foot.

- Cases with concomitant congenital anomalies.

- Cases with history previous surgeries

\section{Clinical and radiological assessment}

Quantification of various components of clubfoot deformity was done using the Pirani score. A standardized method was used to take both pre-treatment and post treatment radiographs, so that the radiographs could be easily compared to avoid any problem of positional change in the values of radiological angles. The child is placed in a sitting position with hips and knee flexed at $90^{\circ}$. The feet are placed as close to plantigrade position as possible with the medial border of the foot as close together as the existing deformities would permit. Two attendants were used for positioning, one to hold the child and other to hold the foot. The beam was directed at the head of the talus at an angle of $30^{\circ}$ to the vertical. Care was taken to prevent any inversion. 


\section{Lateral views}

Lateral views were taken in standing neutral position. Child was placed on a specially designed step stool to take standing lateral views with the lateral border of foot touching the cassette and rays perpendicular to the foot. Lateral views of both feet were taken on separately. Care was taken to prevent inversion of the hind foot and supination or pronation of the forefoot, so that a dead lateral view could be taken. Different radiological angles were calculated by drawing axes of various bones.

\section{On antero-posterior view}

- Talus: Two points were marked anteriorly and posteriorly along the medial and lateral border of the talus. Midpoints of these two set of points were marked and these points were joined by a line to form the long axis of talus.

- Calcaneus: The axis was drawn by marking a line along the lateral border of the calcaneum.

\section{First metatarsal}

Long axis was drawn in a similar way as it is for the talus.

\section{Lateral view}

The long axes of the talus and tibia were drawn in a similar way as it is for the talus in antero-posterior view. The calcaneal line was drawn by marking a line along its inferior border.

\section{The following radiological angles were calculated}

In AP view radiographs:

- Talocalcaneal angle

- Talo First metatarsal angle

In Lateral view radiographs:

- Talocalcaneal

- Tibiocalcaneal

- Tibiotalar

Data was collected, compiled and analysed by using chisquare test, unpaired, paired t-test with the help of SPSS software version 12 . The measurement, parameters and values were generally expressed as mean value \pm 1 Standard Deviation (SD), Median and Range.

\section{Treatment protocol}

A thorough clinical examination of every patient was done at the first presentation as explained and initial radiographs were taken. Pirani scoring was done for all the patients prior to every cast application. Patients underwent weekly cast application in the day care clinic. The babies often cried during the manipulation and hence it was tried that mother should remain close to the baby during all manipulative procedures to comfort them. If it was difficult to comfort the babies even then, oral sedation with promethazine $500 \mathrm{mcg} / \mathrm{kg}$ body wt. or trichlorofos $20 \mathrm{mg} / \mathrm{kg}$ body weight was administered.

An assistant was made to hold the thigh with one hand and the toes with the thumb and index finger of the other hand with knees in 90 degree of flexion during plaster cast application. A two inches or larger cotton bandage depending on the size and age of the child was wrapped starting at the toes and proceeding upwards to the thigh. The plaster that followed was applied snugly over the foot and ankle, for better molding and loosely over the thigh and knee to prevent unnecessary pressure on muscles. Below knee casts were applied first and proper molding of the heel, ankle and malleoli were done.

Then the cast was extended to upper thigh with knees in 90-degree flexion and the leg in a slight external rotation. Patients showing no change in clinical scoring after 3 consecutive casts were considered non-responsive to Ponseti's method of treatment and taken as failed case. These cases were planned for alternative treatment.

\section{Standard Ponseti protocol for cast application}

All components of the clubfoot deformity have to be corrected simultaneously with the exception of the equinus which should be corrected last.

The cavus results from a pronation of the forefoot in relation to the hind foot and is corrected by supinating the forefoot in relation to hind foot and thereby placing it in proper alignment.

While the whole foot is held in supination, it can be gently and gradually abducted under the talus, and secured against rotation in the ankle mortise by applying counter-pressure with the thumb against the lateral aspect of the head of the talus.

The heel varus and foot supination will correct when the entire foot is fully abducted in maximum external rotation under the talus.

The foot should never be everted. After the above is accomplished, the equinus can be corrected by dorsiflexing the foot. The Achilles tendon may need to be subcutaneously sectioned to facilitate this correction.

\section{Tenotomy of achilles tendon}

Tenotomy was undertaken without anaesthesia. It was done by a 15 no. blade, inserted medial to the tendon approximately $2 \mathrm{~cm}$ above the insertion of the tendon. The puncture wound was covered with a small sterile pad 
and well molded cast was applied in maximum dorsiflexion and abduction.

In older children, tenotomy of Achilles tendon was done under vision by giving a small $1 \mathrm{~cm}$ skin incision over the proposed site, to ensure a complete tenotomy.

Post tenotomy cast were removed at three weeks in most of the patients and four weeks in patients aged more than 3 years. However even after 4 weeks further casting for a week was applied in some patients.

\section{Splinting}

Steenbeek foot abduction brace was used in all post tenotomy cases. It was applied for 23 hours a day for first three months in all the patients and advised for night use for another three years.

No strict protocol is present in the available literature regarding the splinting in children of older age group. Bracing compliance is also difficult in the children of older age group. Still due to sincere counselling and regular follow up, most patients were compliant.

\section{RESULTS}

Observations of present study are

\section{Number of cases}

In the study 25 cases were observed in which 14 cases had bilateral clubfeet and 11 had unilateral clubfoot. A total of 29 feet were observed with minimum 6 months follow up.

\section{Age distribution and mean age}

The mean age of cases at presentation was 2.4 years ranging from 3 weeks to 9.4 years.

Table 1: Group wise distribution of cases.

\begin{tabular}{|lll|}
\hline $\begin{array}{l}\text { Age } \\
\text { (In years) }\end{array}$ & $\begin{array}{l}\text { Group-A } \\
\text { (Idiopathic) }\end{array}$ & $\begin{array}{l}\text { Group-B } \\
\text { (Neglected) }\end{array}$ \\
\hline$<1$ & $21(53.84 \%)$ & NIL \\
\hline$>1$ & NIL & $18(46.16)$ \\
\hline
\end{tabular}

Table 2: Laterality among the cases in this study.

\begin{tabular}{|ll|}
\hline Laterality & Number of cases \\
\hline Bilateral & $14(56 \%)$ \\
\hline Unilateral & $11(44 \%)$ \\
\hline
\end{tabular}

\section{Sex distribution}

In this study, there were 20 male and 5 female cases respectively. Sex ratio was $4: 1$.

\section{Laterality of cases}

In this study, there were 14 bilateral and 11 unilateral cases respectively. Among the unilateral cases 7 and 4 belonged to right and left sides respectively (Table 2).

\section{Evaluation of deformities}

Individual components of deformities were evaluated clinically and radiologically preoperatively and post operatively.

\section{Evaluation of equinus component}

Pre-treatment: clinical

Table 3: Equinus ranged from 25 to 60 degrees, with a mean of 44 .

\begin{tabular}{|lll|}
\hline Equinus angle $\left(^{\circ}\right)$ & Number of feet & Percentage \\
\hline$<30^{\circ}$ & 4 & $10.25 \%$ \\
\hline $31-45^{\circ}$ & 15 & $38.46 \%$ \\
\hline$>46^{\circ}$ & 20 & $51.28 \%$ \\
\hline
\end{tabular}

Table 4: Equinus distribution with age.

\begin{tabular}{|ll|}
\hline Age group & Average equines $\left({ }^{\circ}\right)$ \\
\hline$<1$ year & 40.66 \\
\hline$>1$ year & 47.07 \\
\hline
\end{tabular}

\section{Pre-treatment: radiological}

Lateral tibiocalcaneal angle (LTICA) in standing or weight bearing neutral was measured according to Simmons method, as a measure of equinus. The reported $\pm 2 \mathrm{SD}$ at neutral is $55^{\circ}-95^{\circ}$ and an age related decrease does occur.

Table 5: Lateral tibiocalcaneal angle (LTICA) $112^{\circ}-145^{\circ}$. (Mean 126.24).

\begin{tabular}{|lll|}
\hline LTICA $\left(^{\circ}\right)$ & Number of feet & Percentage \\
\hline $90-110$ & 0 & 0 \\
\hline $110-130$ & 28 & 65.85 \\
\hline $130-145$ & 11 & 34.14 \\
\hline
\end{tabular}

Post-treatment: clinical

Table 6: Dorsiflexion angle (DFA) range post treatment.

\begin{tabular}{|lll|}
\hline DFA $\left({ }^{\circ}\right)$ & Number of feet & Percentage \\
\hline 0 to $10^{\circ}$ & 21 & $53.84 \%$ \\
\hline $11^{\circ}$ to $20^{\circ}$ & 18 & $46.15 \%$ \\
\hline$>20^{\circ}$ & 0 & 0 \\
\hline
\end{tabular}

There was no residual equinus in any of the patients. The dorsiflexion ranged from $3^{\circ}-20^{\circ}$ (Mean 11.32). 
Table 7: Average dorsiflexion with age.

\begin{tabular}{|ll|}
\hline Age group & Average angle of dorsiflexion \\
\hline$<1$ year & 12.0 \\
\hline$>1$ year & 10.69 \\
\hline
\end{tabular}

Post-treatment: radiological

Table 8: Post treatment lateral tibiocalcaneal $65^{\circ} \mathbf{- 8 9}^{\circ}$ (Mean 76.76).

\begin{tabular}{|lll|}
\hline Range of LTICA $\left({ }^{\circ}\right)$ & No. of feet & Percentage \\
\hline $60^{\circ}-70^{\circ}$ & 4 & 10.25 \\
\hline $71^{\circ}-80^{\circ}$ & 24 & 61.53 \\
\hline $81^{\circ}-90^{\circ}$ & 11 & 28.20 \\
\hline
\end{tabular}

Table 9: Changes in clinical and radiological values

\begin{tabular}{|llll|}
\hline Angles & Pretreatment & Post-treatment & Difference \\
\hline DFA & $44^{\circ}$ & $11.32^{\circ}$ & $55.32^{\circ}$ \\
\hline LTICA & $126.24^{\circ}$ & $76.76^{\circ}$ & $49.48^{\circ}$ \\
\hline
\end{tabular}

\section{Evaluation of heel varus component}

Pre-treatment: clinical

Table 10: The range of heel varus was $20^{\circ}-50^{\circ}$ (Mean 31.4).

\begin{tabular}{|lll|}
\hline Angle of heel varus $\left(^{\circ}\right)$ & Number of feet & Percentage \\
\hline$<20^{\circ}$ & 0 & $0 \%$ \\
\hline $20-30^{\circ}$ & 16 & $41.02 \%$ \\
\hline $31-40^{\circ}$ & 14 & $35.89 \%$ \\
\hline$>41^{\circ}$ & 09 & $23.07 \%$ \\
\hline
\end{tabular}

Nine feet had varus of more than $41^{\circ}$. The heel varus component was relatively higher in the age group of $>1$ year than those $<1$ year

\section{Pre-treatment: radiological}

Table 11: AP talocalcaneal angles.

\begin{tabular}{|ll|l|}
\hline AP TCA $\left({ }^{\circ}\right)$ & Number of feet & Percentage \\
\hline$<10^{\circ}$ & 28 & $71.79 \%$ \\
\hline $10-20^{\circ}$ & 11 & $28.20 \%$ \\
\hline$>21^{\circ}$ & 0 & $0 \%$ \\
\hline
\end{tabular}

Radiological assessment was done by anteroposterior (AP) talocalcaneal angle for the varus component. This angle reflects the alignment of the hind part of the foot.

It decreases with varus angulation of the hind part of the foot and increases with valgus angulation.

The range of AP talocalcaneal angle was from $0-20^{\circ}$ (Mean 8.16).
Table 12: Pretreatment Lateral talocalcaneal angles.

\begin{tabular}{|c|c|c|}
\hline LTCA $\left(^{\circ}\right)$ & Number of feet & Percentage \\
\hline$<10^{\circ}$ & 28 & $71.79 \%$ \\
\hline $10-20^{\circ}$ & 11 & $28.20 \%$ \\
\hline$>21^{\circ}$ & 0 & $0 \%$ \\
\hline
\end{tabular}

The LTCA is a measure of alignment of hind part of the foot and is decreased when there is varus or equinus of the hind part of the foot or both. The range of LTCA was from $0^{\circ}-20^{\circ}$ (Mean 8.48).

Table 13: Post treatment: Clinical

\begin{tabular}{|lcc|}
\hline Angle of heel varus $\left(^{\circ}\right)$ & Number of feet & Percentage \\
\hline$>0^{\circ}$ & 4 & $10.25 \%$ \\
\hline $0-10^{\circ}$ & 27 & $69.23 \%$ \\
\hline $11-20^{\circ}$ & 8 & $20.51 \%$ \\
\hline
\end{tabular}

The post treatment heel varus ranged from $4^{\circ}-14^{\circ}$. There was no valgus over correction in any of the cases. 3 feet remained corrected only upto neutral and 4 feet remained in varus of maximum 4 degrees.

Three of these were in patients' aged more than 1 years and only one in a patient below of age one year. On follow up of 9 months the varus remained same and did not show any increase. The functional ranges of movement were acceptable in all these feet and were acceptable to the parents and no intervention was done for the same. Mean corrected angle was $6.68^{\circ}$. The average correction of heel varus was decreasing with the increase in age.

\section{Post-treatment: Radiological}

Table 14: APTCA post treatment.

\begin{tabular}{|lll|}
\hline APTCA $\left(^{\circ}\right)$ & Number of feet & Percentage \\
\hline$<10^{\circ}$ & 0 & $0 \%$ \\
\hline $11^{\circ}-20^{\circ}$ & 4 & $10.25 \%$ \\
\hline $21^{\circ}-30^{\circ}$ & 28 & $71.79 \%$ \\
\hline $31^{\circ}-40^{\circ}$ & 7 & $17.94 \%$ \\
\hline
\end{tabular}

Post correction APTCA ranged from $15^{\circ}-35^{\circ}$. (Mean 25.4).

Table 15: LTCA post treatment.

\begin{tabular}{|lll|}
\hline LTCA $\left(^{\circ}\right)$ & Number of feet & Percentage \\
\hline$<10^{\circ}$ & 0 & $0 \%$ \\
\hline $11^{\circ}-20^{\circ}$ & 4 & $10.25 \%$ \\
\hline $21^{\circ}-30^{\circ}$ & 32 & $82.05 \%$ \\
\hline $31^{\circ}-40^{\circ}$ & 2 & $7.7 \%$ \\
\hline
\end{tabular}

Post correction LTCA ranged from $15^{\circ}-40^{\circ}$. (Mean 24.08) 
Table 16: No. of correction casts required across different age groups.

\begin{tabular}{|ll|}
\hline Age group & Number of casts (avg.) \\
\hline$<1$ year & 6.87 \\
\hline$>1$ year & 9.42 \\
\hline
\end{tabular}

The total number of casts applied until final correction ranged from 5 to 11 with a mean of 8.1 casts required achieving full correction. The correlation between age at presentation and total no. of casts required for correction was highly significant. The correlation between the initial Pirani scores and no. of casts required for correction was significant. With the increasing age, higher numbers of casts on an average were required for correction using the Ponseti method.

\section{DISCUSSION}

Idiopathic clubfoot, one of the most common problems in paediatric orthopaedics, is characterized by a complex three-dimensional deformity of the foot. ${ }^{6}$ The treatment of clubfoot is controversial and continues to be one of the biggest challenges in paediatric orthopaedics. ${ }^{7}$ This controversy is due in part to the difficulty in measuring and evaluating the effectiveness of different treatment methods. The heart of the debate lies in a lack of understanding of the functional anatomy of the deformity, the biological response of young connective tissue to injury and repair, and their combined effect on the longterm treatment outcomes.

It was through his attempt to understand the pathophysiology of clubfoot, as well as his ability to learn from the mistakes of his predecessors, that ponseti developed his current method of treatment for clubfoot. His understanding of the anatomy of the tarsus of the normal foot and of the clubfoot was greatly enhanced by the work of Farabeuf's precis de manual operatoire. He had described that, as the foot goes into varus, the calcaneus adducts and inverts under the talus while the cuboid and the navicular adduct and invert in front of the calcaneus and the talar head, respectively.

Later Huson demonstrated that the tarsal joints do not move as single hinges but rotate about moving axes. Motions of the tarsal joints occur simultaneously ${ }^{7-9}$. If the motion of one of the joints is blocked, the others are functionally blocked as well. Based on these concepts, ponseti developed his treatment guidelines. All the components of the clubfoot deformity have to be corrected simultaneously with the exception of the equinus which should be corrected last. ${ }^{8-10}$

The cavus results from a pronation of the forefoot in relation to the hind foot, and is corrected by supinating the forefoot in relation to hind foot and thereby placing it in proper alignment. ${ }^{11-12}$ While the whole foot is held in supination, it can be gently and gradually abducted under the talus, and secured against rotation in the ankle mortise by applying counter-pressure with the thumb against the lateral aspect of the head of the talus. The heel varus and foot supination will correct when the entire foot is fully abducted in maximum external rotation under the talus. ${ }^{13}$ The foot should never be everted. After the above is accomplished, the equinus can be corrected by dorsiflexing the foot. ${ }^{14}$

The achilles tendon may need to be subcutaneously sectioned to facilitate this correction. ${ }^{15-16}$ Ponseti developed and refined his method of serial casting in the 1940's, based on the above principles, but kite's method still remained in vogue till a decade back, when the long term results of ponseti were published. In our study before treatment, before the treatment, the mean pirani score for hind foot was 2.39. Post treatment, all the feet achieved equinus correction beyond neutral. The maximum dorsiflexion that was achieved was $20^{\circ}$, in 1 foot, this patient belonged to the age group $<1$ year. None of the patients achieved dorsiflexion beyond $20^{\circ}$. The average dorsiflexion achieved was $11.32^{\circ}$.

The minimum dorsiflexion achieved was $3^{\circ}$. In 21 feet the dorsiflexion achieved was less than $10^{\circ}$. The final pirani scores after treatment were 0.5 in 10 feet, for equinus and 0 for the rest 29 feet. The mean final pirani score for equinus was 0.115 . Tenotomy of achilles tendon was done in about $70 \%$ feet for the correction of equinus. Only 1 foot required a repeat tenotomy after 3 months of the first one as the correction was not adequate after the first tenotomy. In 1 patient, with bilateral deformity, the equinus component in both feet, did not respond to the ponseti method.

This patient developed a flat top talus as well due to repeated manipulation, as in all 12 casts were applied. The amount of residual equinus was $15^{\circ}$ at the end of casting. Post-surgery the dorsiflexion achieved was $3^{\circ}$ and $5^{\circ}$ respectively in right and left foot. At last follow up, after 9 months the dorsiflexion reduced to just upto neutral and both the feet were stiff with a range of motion less than $10^{\circ}$. But the feet remained plantigrade and the patient was able to wear normal shoes. Otherwise tenotomy was done in patient's upto the age of 9.4 years. Dorsiflexion achieved with ponseti's method reduced consistently as the age of the patient increased.

The correlation between age at presentation and final dorsiflexion achieved was statistically significant using the pearson correlation. The average dorsiflexion achieved in age group less than 1 year was $12.0^{\circ}$ and more than 1 year was 10.69 degree. Radiological improvement correlated well with clinical improvement. Post treatment lat tibiocalcaneal ranged from 65 to 89 degrees with a mean of $76.76^{\circ}$. The change in pre and post treatment ltca was statistically significant. Lourenço AF, Morcuende JA in their study, between 1997 to 2003, of 17 children (24 feet) with congenital idiopathic club foot, mean age of 3.9 years, treated by ponseti's method reported average dorsiflexion of $5^{\circ}$ (range $5^{\circ}-10^{\circ}$ ). In 
comparison to their study our mean age was 2.4 years and our average dorsiflexion at the end of treatment was $11.32^{\circ}$. Before treatment the range of adduction deformity was from $30^{\circ}-62^{\circ}$, with a mean of 42.4 . Rest 13 feet had a score of 4 . None of the feet had a score less than 3 , or an adduction deformity less than $20^{\circ} .30$ feet had a pirani score of 1 for curved lateral border and rest 7 feet had a score of 0.5 at initial presentation. The average pirani scores for curved lateral border were 0.89 . Adduction was found to be higher in the patients of older age group and the correlation between age and initial adduction deformity was statistically significant. The correction of adduction was related with simultaneous correction of heel varus.

By pirani scoring, only 2 feet had a post treatment, curved lateral border score of 0.5 , which could be passively corrected to beyond neutral. None of the feet had any residual adduction deformity or required any surgery for the correction of same. One patient with unilateral involvement, at seven months of follow up, had a relapse with dynamic supination and curved lateral border. The cause for this relapse was noncompliance to bracing protocol. Radiological assessment was done by Talo AP first metatarsal angle (AP T1MT angle) for the forefoot adduction component. Range for anteroposterior Talo first metatarsal angle (T1MT angle), pre correction, was $15^{\circ}-56^{\circ}$ with a mean of $33.76^{\circ}$.

The range for post correction ap $\mathrm{t} 1 \mathrm{mt}$ angle was from $0^{\circ}$ $18^{\circ}$ with a mean of $9^{\circ}$. The range for normal AP T1MT angle as described by simmons is between $0^{\circ}-20^{\circ}$ and all the patients had post correction angles within this range. The change between pre-treatment and post-treatment ap t1mt was statistically significant. In the study by Lourenço AF, Morcuende JA the mean AP T1MT angle was $9.7^{\circ}$. Hence our results were in comparison with their study with respect to the adduction deformity. The range of heel varus was $20^{\circ}-50^{\circ}$, with a mean $31.4^{\circ}$.

Heel varus deformity was significantly higher in patients of older age group. Heel varus correction was seen gradually as the feet were brought into abduction with serial casts. The post-treatment heel varus ranged from $4^{\circ}-14^{\circ}$, there was no valgus over correction in any of the cases. 3 feet remained corrected only upto neutral and 5 feet remained in varus. The mean corrected angle was $6.68^{\circ}$.

The decision for achilles tendon tenotomy was undertaken in some of the feet when the anterior process of calcaneus was palpable but heel varus could not be completely corrected or reached just up to neutral or the hind foot pirani score was approximately 1 . Radiological assessment was done by APTCA. The range of APTCA, pre-correction, was from $0^{\circ}-14^{\circ}$, with mean of 8.16 and SD of 4.34 the post-correction APTCA ranged from 15 to 35 degrees, with a mean of $25.4^{\circ}$. The change of pre and post-treatment APTCA was statistically significant. In the study by Lourenço AF, Morcuende JA, the mean beatson pearson index before treatment was $10^{\circ}$ and after treatment it was $42^{\circ}$. Hence our results were better than their study as our mean beatson pearson index was $51.39^{\circ}$ after correction and we were able to achieve clinical as well as radiological correction in this regard. As in other component deformities of clubfoot, age had a role in delaying the correction of cavus.

Cavus was found to be more resistant to correction in older children, in the age group more than one year. We applied upto 3 casts for cavus in full supination. Despite this, cavus could not be corrected fully in all the feet with 3 casts. After 3 casts, cavus was serially corrected with abduction in supination. The average number of casts applied in full supination with respect to different age groups was as follows, in $<1$ year it was 1.5 , in $>1$ year it was 2.18. Till last follow up, the cavus remained corrected and no recurrence of this deformity was seen. The average pirani scores for medial crease showed a declining trend with age.

The average pre-treatment pirani scores for medial crease was 0.77 in children of age group $<1$ year, 0.66 in children of age group $>1$ year. Hence, despite severe adduction and cavus deformity the average score for medial crease was lower in the children of older age group. This remains to be one of the fallacies of pirani scoring in the older age group. It correlated well with the correction of adduction deformity. The final pirani for medial crease were 0 in all the cases post correction. The average pirani scores pre-treatment, for posterior crease with respect to the age was as follows. In the age group of $<1$ year it was 0.85 .

In the age group of $>1$ year it was 0.71 . Despite severe equinus in the children of older age group the scores for posterior crease were lower. Similar to medial crease, even posterior crease had a fallacious low value as per the pirani scoring in older children and tends to under estimate the deformity. The final pirani scores for posterior crease were 0 in all the cases and it correlated well with the correction of equinus. The change in pirani score between pre and post treatment values was found to be statistically significant. In our study, the total number of casts applied, to achieve final correction, ranged from 5 to 11 with a mean of 8.1 casts having been required.

We used the classic two hand ponseti technique for casting but the initial stretching was prolonged to at least five minutes as the soft tissue in elder children were less yielding. Above knee cast was used in all children and a sequential correction was done. Casts were changed every week. End point of manipulation and casting was achieved when no further correction on scoring was noted with three serial casts or the mid foot and hind foot scores seemed corrected enough for tenotomy. In the study by Lourenço AF, Morcuende JA, correction was obtained with a mean of nine casts ( 7 to 12 ), but they used a modified ponseti method with fortnightly change of casts, hence there average duration of immobilization in a cast 
was higher than our study. In the study by Alam S, Kumar A, of 25 feet in children aged above 7 yrs and treated by ponseti method the average no. Of casts required to achieve full correction was 12.1 . Hence the number of casts applied in our study for the final correction was in comparison to the above mentioned, only two studies, in the available literature on the use of ponseti method in neglected clubfoot.

\section{CONCLUSION}

Improvement obtained by manipulation is maintained by immobilizing the foot in a plaster cast for five to seven days. With immobilization, the tight medial and posterior tarsal ligaments tend to yield. The deformity can be gradually corrected with further manipulations and five to six changes of cast. The equines are corrected by dorsiflexing the fully abducted foot. Percutaneous tenotomy of the Achilles tendon is often necessary to completely correct the equines. Dennis-Browne split is applied to the foot until the age of three to four years old.

The Ponseti method delivers excellent correction of clubfoot without the associated risks and complications of major foot surgery. Moreover, studies show that patients treated with the Ponseti method has the upper hand in treating clubfoot than those treated by other conservative methods and the method provides more flexible foot and ankle than those treated surgically, Dennis-Brown splint is a must in this method to prevent relapses. Tibialis anterior tendon transfer can be done in case of dynamic deformity.

Funding: No funding sources

Conflict of interest: None declared

Ethical approval: The study was approved by the institutional ethics committee

\section{REFERENCES}

1. Laaveg SZ, Ponseti IV. Long term results of congenital clubfoot. J Bone Joint Surg. 1980;62:2331.

2. Ponseti IV. Common error in the treatment of congenital clubfoot. Int Orthop. 1997;21:137-41.
3. Kite JH. Some suggestions on treatment of clubfoot by casts. J Bone Joint Surg Am. 1963;45:406-12.

4. Kite JH. Principles involved in the treatment of clubfoot. J Bone Joint Surg Am. 2003;85:1847.

5. Simons GW. Analytical radiography and the progressive approach in talipes equino varus Orthop Clin of North Am. 1977;59:485-9.

6. Attenborough CG. Severe congenital talipes equino varus. J Bone Joint Surg. 1948;13:16-9.

7. Turco VJ. Surgical correction of resistant clubfoot. One-stage posteromedial release with internal fixation: a preliminary report. J Bone Jt Surg Am. 1971;53:477-97.

8. Mackay DW. New concepts of and approach to clubfoot treatment section II correction of clubfoot. J Paed Ortho. 1983;3:10.

9. Simons GW. Complete subtalar release in clubfeet part-II comparison with less extensive procedures. J Bone Joint Surg 1985;1056-65.

10. Dobbs MB. J Bone Jt Surg Am. 2006;88:986-96.

11. Ippolito E. Long term comparatives results in patients with congenital clubfoot treated with two different protocols. J Bone Joint Surg Am. 2003;85:1286-94.

12. Ponseti IV. Editorial clubfoot management. J Paed Orthop 2000; 20:699-700.

13. Wynne-Davies R. Talipes equino varus. A review of eighty-four cases after completion of treatment. J Bone Jt Surg.1964;46:464.

14. Honein MA. Family history, maternal smoking, and clubfoot: an indication of a gene-environment interaction. Am J Epidemiol. 2000;152:658-65.

15. Tredwell SJ. Review of the effect of early amniocentesis on foot deformity in the neonate. $\mathbf{J}$ Paed Orthop. 2001;21:636-41.

16. Philip J. Late first-trimester invasive prenatal diagnosis: results of an international randomized trial. Obs-Gyn. 2004;103:1164-73.

Cite this article as: Kumar R, Anshupriya. Management of idiopathic clubfoot by Ponseti's method: a comparative clinical study on toddlers with radiological correlation. Int J Res Orthop 2016;2:52-9. 